\title{
Quantitative genetic analysis of dispersal in Epiphyas postvittana. II. Genetic covariations between flight capacity and life-history traits
}

\author{
HAINAN GU \& WIJESIRI DANTHANARAYANA \\ Department of Zoology, The University of New England, Armidale, NSW 2351, Australia
}

\begin{abstract}
On the basis of investigations of environmental and genetic variation in flight capacity of the light brown apple moth, Epiphyas postvittana (Walker) (Tortricidae), genetic covariations between flight capacity and life-history traits in this species were studied by means of sibling analysis and artificial selection. Both sibling analysis and artificial selection strongly evidenced the existence of additive genetic covariances between flight capacity and life-history traits such as developmental time, adult body weight at emergence, age at first reproduction and fecundity. Flight capacity was negatively correlated with adult body weight, the number of eggs laid during the first 5 days of adult life and total fecundity, whereas it was positively correlated with developmental time from egg-hatch to adult emergence, age at first reproduction and adult life span. These results, which indicate that increased flight capacity is accompanied by a slower developmental rate, smaller body size, delayed oviposition and less fecundity, resulting in a lower population growth rate, contrast with the colonizing syndrome that highly mobile individuals show rapid development, early reproduction and high fecundity. It is suggested that the existence of genetic 'trade-offs' between flight capacity and these life-history traits is partially responsible for the general occurrence of variability in dispersal capacity by flight in this species.
\end{abstract}

Keywords: Dispersal, Epiphyas postvittana, flight capacity, genetic cavariation, life-history traits.

\section{Introduction}

Dispersal is an adaptation to survival and reproduction in species that inhabit changing environments (Tauber et al., 1986), and natural selection would be expected to produce a suite of life-history traits that co-evolve with dispersal (Dingle, 1986). To understand the potential and constraints for phenotypic evolution of dispersal by flight in response to a particular selective regimen, therefore, knowledge of both genetic variations and covariations in flight and life-history traits, especially the components of fitness (Loeschcke, 1987), must be known.

In a separate paper (Gu \& Danthanarayana, 1991), the investigation into the genetic variation in flight capacity in the light brown apple moth, Epiphyas postvittana (Walker) (Tortricidae) is described. Quantitative genetic analyses have shown that there is a substantial additive genetic variance for flight capacity. The importance of demonstrating additive genetic variance is that it reveals the potential of a given trait to respond to selection (Falconer, 1981). However, the response to natural selection is also governed by the additive genetic variance-covariance relationships among different traits (Lande, 1979; Rose, 1982, 1983, 1985).

The purpose of the present study is to investigate whether there are significant genetic covariations between flight capacity and some life-history traits which could influence phenotypic evolution, and whether the pattern of genetic covariance structure within a population, which characterizes colonizing populations or species (Safriel \& Ritte, 1980; Parsons, 1983 ), occurs in E. postvittana. To address these issues, quantitative genetic analysis was performed to examine the genetic correlations between flight capacity and several life-history traits in natural populations. Populations differentiated by artificial selection on flight capacity (Gu \& Danthanarayana, 1991) were assayed 
for correlated responses in these life-history traits and for the intrinsic rate of natural increase, one of the most commonly used measurements of fitness.

\section{Materials and methods}

\section{Estimation of genetic correlation}

In a nested experiment, as described by $\mathrm{Gu} \&$ Danthanarayana (1991), not only was flight capacity tested, but also several life-history traits were measured on the same individuals. Each female was weighed at the same time on the day of emergence on an electronic balance and was then paired with a male within an oviposition chamber. Records were taken daily for egg-laying and survival status. Thus, the data from each individual allow estimation of both genetic variances in individual traits to calculate their heritabilities (Gu \& Danthanarayana, 1991) and genetic covariances between different traits to calculate genetic correlations. The total phenotypic variances of traits and covariances of pairs of traits were broken down to components of variance and covariance, attributable to the effects of sire and dams within sire, and individual offspring of the same dam (Becker, 1984; Falconer, 1981). LSMLMW, a general purpose 'mixed model least-squares' computer program (Harvey, 1970, 1988) was used to estimate the variance and covariance components. Genetic correlations were computed from these components in each case by simply dividing the family covariance component estimate for the two traits $(x$ and $y$ ) by the geometric mean of the two 'family' variance component (paternal half-sib) estimates. The calculations were based on $\log _{10}$ transformed data. A two-tailed $t$-test (Sokal \& Rohlf, 1981) was performed to determine if the estimated genetic correlations were different from zero.

\section{Estimation of correlated responses in life-history traits}

To test a correlated response to selection for flight potential, which is defined as a change in the mean phenotype value of one trait that accompanies a response to selection in another trait (Falconer, 1981), some of the life-history traits (such as adult body weight at emergence, adult lifespan, age at first reproduction, fecundity and oviposition pattern) were measured on moths of long-flying, short-flying and control lines in generations $4,7,8$ and 9 of selection. In each of these generations, 20 pairs of male and female moths were randomly sampled and maintained within oviposition chambers, each holding a single pair, in a controlled environment with a temperature of
$20 \pm 0.5^{\circ} \mathrm{C}, 60-70$ per cent r.h. and a light cycle of L14:D10, unless otherwise stated. These moths were fed with water and checked daily for survival and oviposition.

\section{Estimation of population growth parameters}

The experiment to estimate the intrinsic rate of natural increase and associated parameters was started with eggs newly laid by moths randomly sampled from the long- and short-flying lines in generation 12 (selection was relaxed in generation 11). At the age of 3 days, egg masses were examined for fertilization and then checks for hatching were made twice a day (morning and evening). The ratios of hatched larvae to fertilized eggs were calculated as the survivorship rates at egg stage. On the day of hatching, larvae were singly transferred into plastic cups ( $4 \mathrm{~cm}$ in diameter and $3.8 \mathrm{~cm}$ high) with $5 \mathrm{~g}$ of artificial diet (Shorey \& Hale, 1965) per cup. At late larval stages, daily checks were made of pupation and emergence. On the day of emergence, male and female moths were paired singly within oviposition chambers. Records were taken daily for egg deposition and survival status of moths. The experiment was carried out in a controlled envrironment with a temperature of $20 \pm 0.5^{\circ} \mathrm{C}, 60-70$ per cent r.h. and a light regime of L14:D10.

Tables of age-specific survival $\left(l_{x}\right)$ and age-specific fecundity $\left(m_{x}\right)$ were constructed for each of the selected lines using the methods described by Birch (1948). The age-specific survival $\left(l_{x}\right)$ is the probability of survival to the midpoint of the stage or age interval $(x)$ and was corrected for the sex ratio of successfully emerging adults. The age-specific fecundity $\left(m_{x}\right)$ was corrected for sex ratio of $1: 1$. Based on the constructed life tables, the approximate estimates of the intrinsic rate of natural increase $\left(r_{m}\right)$ and the associated parameters were calculated using the following formulae (Birch, 1948):

$R_{0}=\Sigma l_{x} m_{x}$, $T=\left(\Sigma l_{x} m_{x} x\right) /\left(\Sigma l_{x} m_{x}\right)$

and

$r_{m}=\operatorname{loge}\left(R_{0}\right) / T$

where $R_{0}$ is the net reproductive rate and $T$ is the cohort generation time.

\section{Results}

Genetic correlations between flight capacity and lifehistory traits

Both positive and negative genetic correlations of varying magnitudes occurred between flight capacity and 
life-history traits (Table 1). Moreover, the genetic covariance structure was shown to differ between the populations at different laboratory temperatures. Flight capacity was significantly positively correlated with developmental time (DT) and age at first reproduction (AFR) in both populations at $23^{\circ} \mathrm{C}$ and in the Melbourne population at $28^{\circ} \mathrm{C}$. It was also found to be significantly positively correlated with adult life span (ALS), and negatively with adult body weight at emergence (BW) in the Canberra population at both temperatures and in the Melbourne population at $28^{\circ} \mathrm{C}$, with the exception of a positive correlation between flight capacity and BW in the Canberra population at $28^{\circ} \mathrm{C}$. For the reproductive traits flight capacity was negatively correlated with the number of eggs laid dur- ing the first 5 days of adult life (F5D) but only significantly in the Melbourne population at $28^{\circ} \mathrm{C}$; it was significantly negatively correlated with the number of eggs laid at the late stage of adult life (FRP) in the Melbourne population at both temperatures but positively in the Canberra population at $28^{\circ} \mathrm{C}$. Inclusively, flight capacity was negatively correlated with total fecundity (TF) in all cases, but only significantly in the Canberra population at $23^{\circ} \mathrm{C}$ and in Melbourne at $28^{\circ} \mathrm{C}$.

\section{Correlated response in life-history traits}

Data for life-history traits (such as adult body weight at emergence, adult life span, age at first reproduction and fecundity, recorded for samples taken from the

Table 1 Genetic correlation estimates $( \pm$ S.E.) from paternal half-sibs between flight capacity and life-history traits in Canberra and Melbourne populations at $23^{\circ}$ and $28^{\circ} \mathrm{C}$

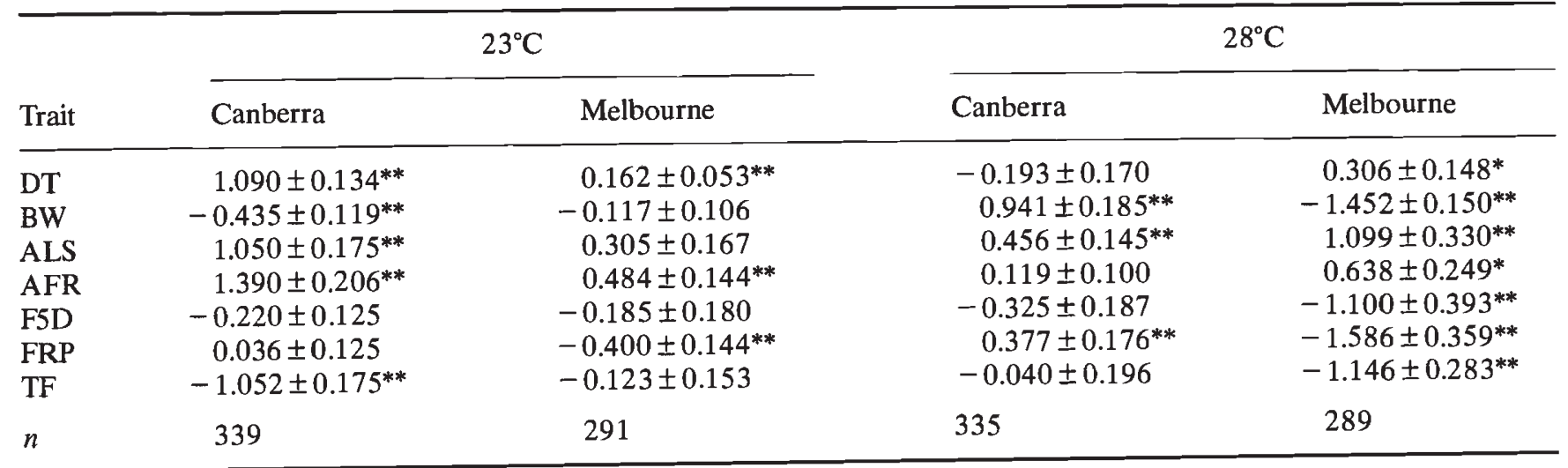

${ }^{*} P<0.05,{ }^{* *} P<0.01$.

$\mathrm{DT}=$ development time from egg hatch to adult emergence; $\mathrm{BW}=$ adult body weight at emergence; $\mathrm{ALS}=$ adult life span; $\mathrm{AFR}=$ age at first reproduction; $\mathrm{F} 5 \mathrm{D}=$ eggs laid during the first 5 days of adult life; FRP= eggs laid from day 6 to the end of adult life; $\mathrm{TF}=$ total fecundity.

Table 2 Life-history traits of moths from three lines in generation 4 of selection $(n=20)$ at $20 \pm 0.5^{\circ} \mathrm{C}$

\begin{tabular}{lllll}
\hline Trait & Long & Control & Short & $F$ \\
\hline $\begin{array}{c}\text { Body weight } \\
\text { of female }(\mathrm{mg})\end{array}$ & $27.0 \pm 0.89$ & $26.0 \pm 1.36$ & $25.8 \pm 1.45$ & $<1$ \\
$\begin{array}{c}\text { Body weight } \\
\text { of male }(\mathrm{mg})\end{array}$ & $12.4 \pm 0.52^{a}$ & $11.8 \pm 0.57^{a}$ & $14.0 \pm 0.43^{b}$ & $5.3^{*}$ \\
$\begin{array}{c}\text { Life span of } \\
\text { female (days) }\end{array}$ & $20.0 \pm 1.27$ & $21.6 \pm 1.76$ & $19.0 \pm 1.17$ & $<1$ \\
$\begin{array}{c}\text { Age at first repro- } \\
\text { duction(days) }\end{array}$ & $0.65 \pm 0.15$ & $0.9 \pm 0.34$ & $0.85 \pm 0.24$ & $<1$ \\
$\begin{array}{c}\text { Fecundity } \\
\text { ncuns }\end{array}$ & $380 \pm 42.6$ & $419.9 \pm 52.0$ & $436.6 \pm 35.0$ & $<1$ \\
\hline
\end{tabular}

$* P<0.05$. Note: Values are means \pm S.E. A multiple range test (SNK, Zar, 1974) was used to determine differences in life-history traits among lines which are indicated by lower case superscripts. Means with different superscript letters are significantly different at $P<0.05$; the alphabetical order indicates increasing values of means. The same test was used for the data from other generations. 
long-, short-flying and control lines in generations 4,7 , 8 and 9 of selection) are shown in Tables 2-5.

By generation 4 , selection on flight capacity did not result in significant differences in these life-history traits between the two selected lines except for adult body weight, although in this generation flight capacities of both males and females in the two selected lines had significantly diverged from the

Table 3 Life-history traits of moths from three lines in generation 7 of selection $(n=20)$ at $23 \pm 0.5^{\circ} \mathrm{C}$

\begin{tabular}{llllc}
\hline Trait & Long & Control & Short & $F$ \\
\hline $\begin{array}{c}\text { Body weight } \\
\text { of female }(\mathrm{mg})\end{array}$ & $26.2 \pm 1.08^{a}$ & $30.7 \pm 1.36^{b}$ & $29.8 \pm 0.80^{b}$ & $4.1^{*}$ \\
$\begin{array}{c}\text { Body weight } \\
\text { of male }(\mathrm{mg})\end{array}$ & $12.2 \pm 0.37^{a}$ & $14.1 \pm 0.48^{b}$ & $15.1 \pm 0.48^{b}$ & $11.7^{*}$ \\
$\begin{array}{c}\text { Life span of } \\
\text { female (days) }\end{array}$ & $13.2 \pm 1.15$ & $16.4 \pm 1.31$ & $14.9 \pm 1.36$ & 3.0 \\
$\begin{array}{c}\text { Age at first repro- } \\
\text { duction (days) }\end{array}$ & $0.84 \pm 0.56^{a}$ & $1.94 \pm 0.70^{b}$ & $1.10 \pm 0.23^{a}$ & $4.2^{*}$ \\
\begin{tabular}{l} 
Fecundity \\
\hline
\end{tabular} & $254.5 \pm 45.7^{a}$ & $344.4 \pm 52.1^{b}$ & $298.1 \pm 47.9^{b}$ & $4.7^{*}$ \\
\hline
\end{tabular}

${ }^{*} P<0.05$.

Table 4 Life-history traits of moths from three lines in generation 8 of selection $(n=20)$ at $20 \pm 0.5^{\circ} \mathrm{C}$

\begin{tabular}{lcccc}
\hline Trait & Long & Control & Short & $F$ \\
\hline $\begin{array}{c}\text { Body weight } \\
\text { of female }(\mathrm{mg})\end{array}$ & $25.7 \pm 0.60^{a}$ & $31.1 \pm 0.71^{b}$ & $33.3 \pm 0.69^{c}$ & $34.4^{* *}$ \\
$\begin{array}{c}\text { Body weight } \\
\text { of male (mg) }\end{array}$ & $12.3 \pm 0.31^{a}$ & $12.5 \pm 0.37^{a}$ & $13.7 \pm 0.28^{b}$ & $5.3^{*}$ \\
$\begin{array}{c}\text { Life span of } \\
\text { female (days) }\end{array}$ & $20.5 \pm 2.01$ & $23.6 \pm 1.45$ & $20.1 \pm 1.44$ & 1.4 \\
$\begin{array}{c}\text { Life span of } \\
\text { male (days) }\end{array}$ & $16.9 \pm 1.41$ & $21.3 \pm 1.63$ & $19.4 \pm 1.16$ & 2.4 \\
$\begin{array}{c}\text { Age at first repro- } \\
\text { duction (days) }\end{array}$ & $1.6 \pm 0.37^{c}$ & $0 . \pm 0.23^{b}$ & $0.3 \pm 0.13^{a}$ & $6.1^{*}$ \\
\begin{tabular}{c} 
Fecundity \\
\hline
\end{tabular} & $270.3 \pm 45.6^{a}$ & $479.0 \pm 37.4^{b}$ & $529.9 \pm 53.5^{b}$ & $9.0^{*}$ \\
\hline
\end{tabular}

${ }^{*} P<0.05,{ }^{* *} P<0.01$.

Table 5 Life-history traits of moths from three lines in generation 9 of selection $(n=20)$ at $20 \pm 0.5^{\circ} \mathrm{C}$

\begin{tabular}{lcccc}
\hline Trait & Long & Control & Short & $F$ \\
\hline $\begin{array}{c}\text { Body weight } \\
\text { of female }(\mathrm{mg})\end{array}$ & $30.4 \pm 0.66$ & $30.2 \pm 0.69$ & $30.2 \pm 0.73$ & $<1$ \\
$\begin{array}{c}\text { Body weight } \\
\text { of male }(\mathrm{mg})\end{array}$ & $12.9 \pm 0.26$ & $13.7 \pm 0.36$ & $13.5 \pm 0.26$ & 1.9 \\
$\begin{array}{c}\text { Life span of } \\
\text { female (days) }\end{array}$ & $18.7 \pm 1.54$ & $15.5 \pm 1.38$ & $14.3 \pm 1.40$ & 2.5 \\
$\begin{array}{c}\text { Life span of } \\
\text { male (days) }\end{array}$ & $18.7 \pm 0.93$ & $14.6 \pm 1.13$ & $16.1 \pm 1.55$ & 2.8 \\
$\begin{array}{c}\text { Age at first repro- } \\
\text { duction (days) }\end{array}$ & $1.4 \pm 0.35^{c}$ & $0.5 \pm 0.16^{b}$ & $0.3 \pm 0.11^{a}$ & $6.5^{*}$ \\
\begin{tabular}{l} 
Fecundity \\
\hline
\end{tabular} & $238.3 \pm 39.7^{a}$ & $357.9 \pm 59.2^{b}$ & $499.6 \pm 49.2^{c}$ & $4.5^{*}$ \\
\hline
\end{tabular}

${ }^{*} P<0.05$. 
control (Mann-Whitney $U$-test, $W=7636.5, P<0.001$ in females and $W=10578.0, P<0.001$ in males between strong line and control; $W=11093.5$, $P<0.001$ in females and $W=13370.5, P<0.001$ in males between weak line and control) (Sokal \& Rohlf, 1981). However, in generation 7 , body weight and fecundity of moths diverged between the selected lines, as compared with those in the control; in generation 8, all examined traits except for adult life span in the two selected lines significantly diverged in opposite directions from those of the control line. In generation 9, on the other hand, only age at first reproduction and fecundity were significantly different among the three lines.

The daily oviposition patterns of moths in generations 4, 7, 8 and 9 are shown in Figs 1 and 2. Statistical analyses (Gurevitch \& Chester, 1986) showed that there were no significant differences among linear $(F=0.02)$, quadratic $(F=0.72)$, cubic $(F=0.58)$ or total selection effect $(F=1.01$, d.f. $=2,59, P>0.05)$ among the long-, short-flying and control lines in generation 4; however, significant differences existed between the quadratic trends $(F=4.63$, d.f. $=2,57$, $P<0.05)$ and for total selection effect $(F=11.81$, d.f. $=2,57, P<0.01)$ among the three lines in generation 8 , as well as in generations 7 and 9 . This indicates

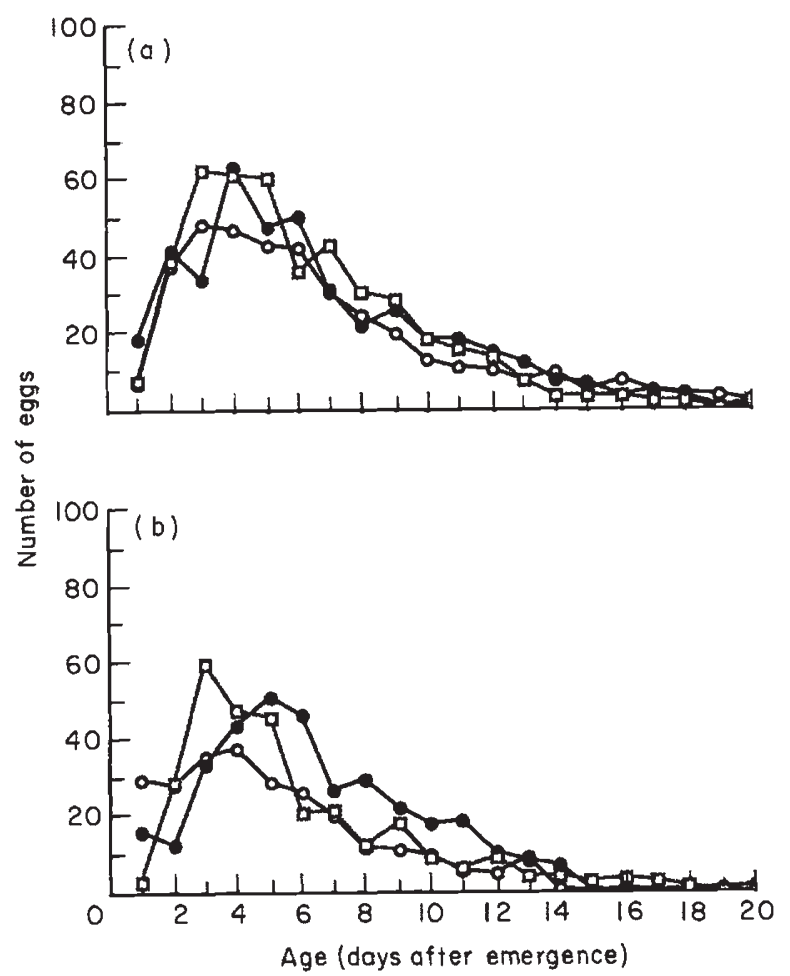

Fig. 1 Daily oviposition pattern of moths from long-flying

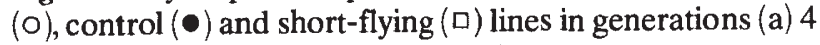
and (b) 7 of selection on flight capacity.

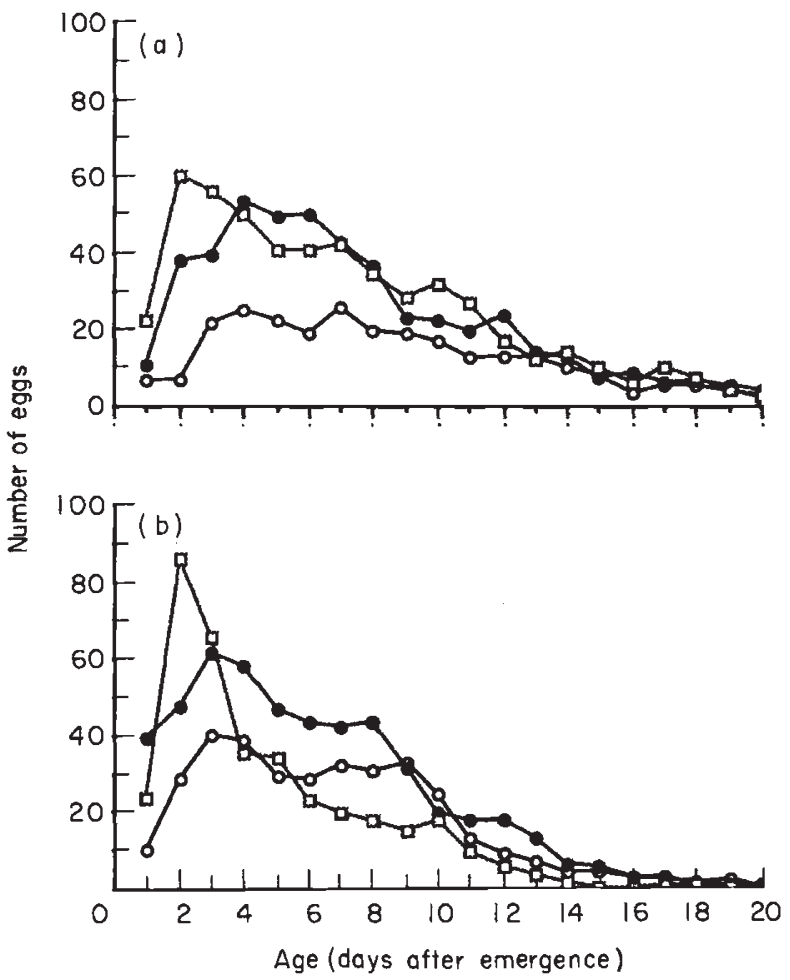

Fig. 2 Daily oviposition pattern of moths from long-flying

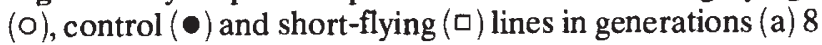
and (b) 9 of selection on flight capacity.

that oviposition patterns of moths from the three lines differ significantly in generations 7,8 and 9 , with the peak of egg-laying more delayed in the long-flying line, but occurring earlier in the short-flying line due to successive selections on flight potential.

Obviously, selection for increased flight capacity caused a longer pre-oviposition period and reduced fecundity, and vice versa in the case of selection for decreased flight capacity.

\section{The population growth parameters}

The mean durations of immature stages (egg, larva and pupa) are shown in Table 6. Clearly, individuals of the long-flying line developed at a slower rate at immature stages, as compared with those of the short-flying line, with the significant difference in developmental rate occurring at larval and pupal stages.

The proportions of survivors at immature stages and the ratios of female to male moths were also found to differ, to some extent, between the two selected lines (Table 7). The survivorship rates at both egg and larval stages were higher in the long-flying line than in the short-flying line, but the rate at pupal stage and the ratio of females to males were greater in the latter than in the former. 
Table 6 Comparison of developmental periods (days) between the long- and shortflying lines at immature stages with sample sizes in parentheses

\begin{tabular}{|c|c|c|c|c|c|}
\hline & Long & Short & $t$ & d.f. & $P$ \\
\hline Egg & $\begin{array}{l}9.27 \pm 0.03 \\
(259)\end{array}$ & $\begin{array}{l}9.25 \pm 0.03 \\
(229)\end{array}$ & 0.47 & 473.2 & 0.64 \\
\hline Female larva & $\begin{array}{l}34.73 \pm 0.70 \\
(37)\end{array}$ & $\begin{array}{l}31.50 \pm 0.34 \\
(41)\end{array}$ & 4.14 & 52.1 & 0.0001 \\
\hline Male larva & $\begin{array}{l}30.44 \pm 0.38 \\
(55)\end{array}$ & $\begin{array}{l}27.93 \pm 0.38 \\
(40)\end{array}$ & 4.67 & 90.3 & 0.0000 \\
\hline Female pupa & $\begin{array}{l}12.16 \pm 0.16 \\
(32)\end{array}$ & $\begin{array}{l}11.55 \pm 0.09 \\
(40)\end{array}$ & 3.22 & 50.8 & 0.0022 \\
\hline Male pupa & $\begin{array}{l}12.62 \pm 0.13 \\
(50)\end{array}$ & $\begin{array}{l}12.35 \pm 0.12 \\
(40)\end{array}$ & 1.57 & 88.0 & 0.12 \\
\hline Total of female & $54.71 \pm 0.48$ & $51.81 \pm 0.40$ & 3.95 & 58.0 & 0.0002 \\
\hline Total of male & $52.41 \pm 0.34$ & $49.50 \pm 0.41$ & 4.03 & 85.9 & 0.0001 \\
\hline
\end{tabular}

Table 7 Survivorship rates of immature stages in long- and short-flying lines with sample sizes in parentheses

\begin{tabular}{lll}
\hline & Long & Short \\
\hline Egg & $0.8382(309)$ & $0.8092(283)$ \\
Larva & $0.7419(124)$ & $0.6532(124)$ \\
Pupa & $0.8804(92)$ & $0.9506(81)$ \\
Ratio of female moths & $0.3827(81)$ & $0.5065(77)$ \\
\hline
\end{tabular}

In addition to the differences in developmental rate, survivorship and sex ratio, the age-specific birth schedules $\left(m_{x}\right)$ of long and short fliers differed substantially (Fig. 3). Short fliers reproduced earlier in adult life than did long fliers which delayed their reproductive effort. The reproductive delay in the long fliers is evidenced by a comparison between the curve patterns of the long and short fliers. The reproductive functions $\left(l_{x} m_{x}\right)$, which combine age-specific survivorship $\left(l_{x}\right)$ and fecundity $\left(m_{x}\right)$, are presented in Fig. 3 for the two forms. Not only is the area under each curve (net reproductive rate $=R_{0}$ ) much greater for short fliers than for long ones, but also the peak of the reproductive function is delayed for long fliers.

All these differences in life-history traits between the two forms greatly influenced the population growth parameters that are summarized in Table 8. In comparison to the short-flying population, the long-flying one had a longer generation time $(T)$, but smaller net reproductive rate $\left(R_{0}\right)$ and intrinsic rate of natural increase $\left(r_{m}\right)$.

\section{Discussion}

Despite differences in magnitude and even sign of genetic correlations estimated from the two natural
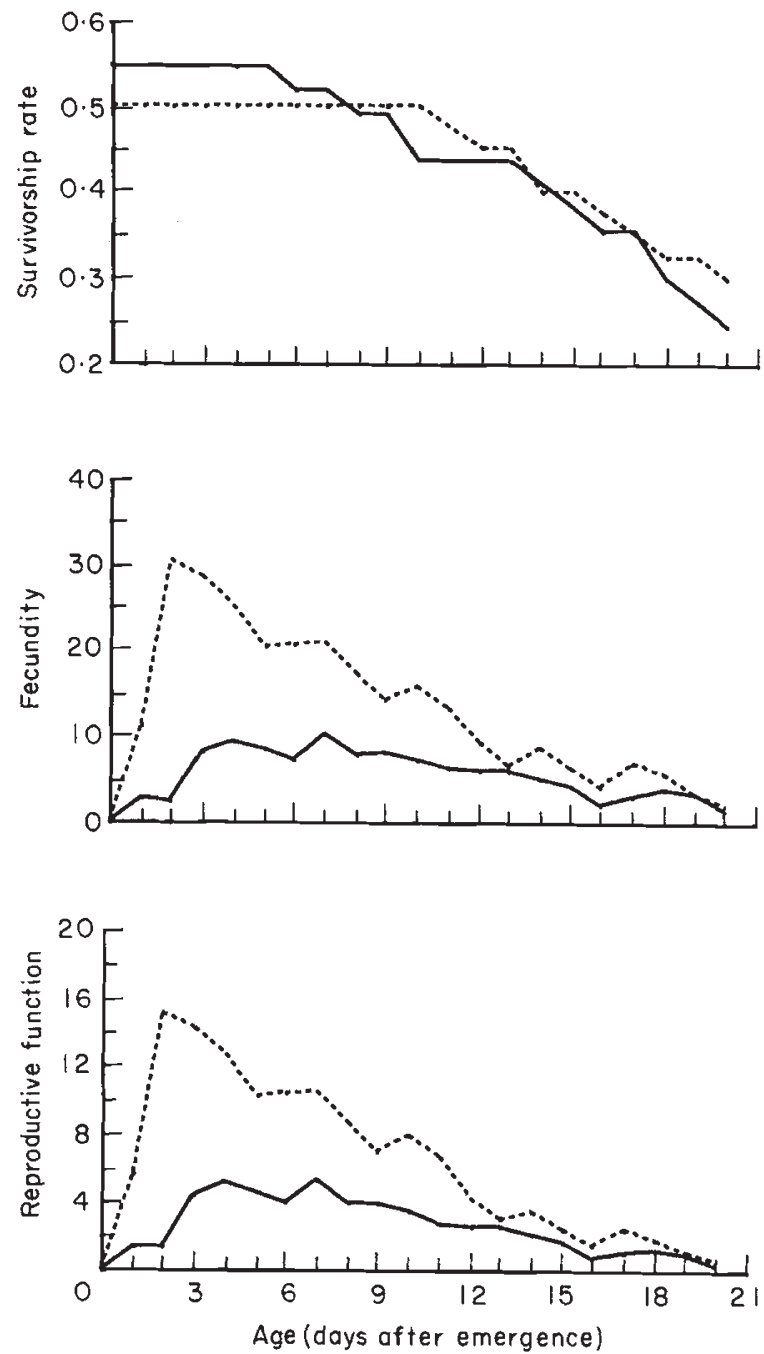

Fig. 3 Survivorship $\left(l_{m}\right)$, fecundity $\left(m_{x}\right)$ and reproductive function $\left(l_{x} m_{x}\right)$ schedules for long- $(-)$ and short-fliers $(---)$. 
Table 8 Population parameters of long- and short-flying lines

\begin{tabular}{lcc}
\hline & Long & \multicolumn{1}{c}{ Short } \\
\hline Net reproductive rate $\left(R_{0}\right)$ & 54.41 & 131.22 \\
Generation time $(T$, day $)$ & 63.87 & 58.54 \\
Intrinsic rate of natural & & \\
increase $\left(r_{m}\right)$ & 0.0626 & 0.0833 \\
\hline
\end{tabular}

populations at two laboratory temperatures, the flight capacity of $E$. postvittana moths was shown to be significantly correlated with most of these examined lifehistory traits, whether positively or negatively (Table 1). The inconsistency in these estimated genetic correlations between the two populations may be attributable to the different genetic structure and/or differential response to environmental temperature of these populations. Such an inconsistency is also reflected in genetic correlations among these life-history traits, which will be reported separately $(\mathrm{H}$. Gu \& W. Danthanarayana, in preparation). Indeed, both genetic differentiation of natural populations and genotype-environment interaction in flight and life-history traits have been detected in this species $(\mathrm{H} . \mathrm{Gu} \& \mathrm{~W}$. Danthanarayana, in preparation). On the other hand, failure to obtain consistent genetic correlations for flight capacity with developmental time and with adult body weight for the Canberra population at the two laboratory temperatures could be caused by the environmental effect, as Service \& Rose (1985) pointed out, or sampling errors. These suggest that the results from the sib analysis should be interpreted cautiously and that the extrapolation of these results to situations that are different from those under which they were estimated may be misleading.

The genetic correlations between flight capacity and life-history traits were largely confirmed by correlated responses in the selection experiment on the Melbourne population. It was found that there were differences in life-history traits of the moths from the populations differentiated by artificial selection on flight capacity (Tables 3-5). The moths of both sexes from the long-flying line needed a much longer time to mature, as compared with those from the short-flying line, but the significant difference occurred only at the larval and pupal stages (Table 6). This justifies the measurement for development time from egg-hatching to adult emergence used in the nested experiment. The differences in life-history traits between long and short fliers were also manifested in age at first reproduction and fecundity, with the result that the long fliers delay reproduction and lay less eggs in comparison to short fliers.
The significant divergence between the two selected lines in developmental time, age at first reproduction and fecundity, as well as in flight capacity, is expected in the light of the existence of additive genetic covariances between flight capacity and these traits in natural populations. As changes in developmental time, age at first reproduction and fecundity were detected as correlated responses to selection on flight potential, a portion of the observed genetic variation is likely to be due to segregating alleles that simultaneously affect these traits by pleiotropy (Falconer, 1981). Although the observed changes may partly be the result of random genetic drift and some inbreeding effect inevitably occurred during the establishment of the selected lines, the correlated responses must be mainly the result of genetic correlations between flight capacity and the various traits, as over the 10 generations these traits in the control (unselected line) remained unchanged.

The genetic correlations among developmental time, adult body weight, age at first reproduction, fecundity and flight capacity suggests that particular combinations of these traits are selected against or selected for in the natural population. These results, which indicate that increased flight capacity is correlated with slower developmental rate, smaller body size, delayed oviposition and less fecundity, resulting in a lower population growth rate, contrast with the colonizing syndrome that highly mobile individuals are characterized by rapid development, early reproduction and high fecundity (Safriel \& Ritte, 1980).

In the sense that genes with negative pleiotropic effects on two traits control the energy partitioning process at the physiological level (Sibly \& Calow, 1986), in the long-flying (highly mobile) individuals of $E$. postvittana, the consequence of the partitioning process might be that less energy is available for development, body size maintenance and reproduction, hence the larval and pupal development period should increase, the body size of adults and the daily oviposition rate should decrease in comparison with short-flying individuals. These suggest the existence of 'trade-offs' between flight capacity and life-history traits.

Phenotypic trade-offs between flight capacity and life-history traits have been reported for a variety of insect species or populations (see review in Denno et al., 1989), although there are examples in which high flight capacity is accompanied by rapid development, early reproduction and high fecundity (Ritte \& Lavie, 1977; Lavie \& Ritte, 1978; Hegmann \& Dingle, 1982; Palmer, 1985; Dingle et al., 1986; Zirkle, et al., 1988). The trade-offs are supposed to be of significance to the evolution and maintenance of flight polymorphism in 
insects (Roff, 1984, 1990; Denno et al., 1989). Obviously, the experimental demonstration of such trade-offs genetically, that is the detection of negative genetic correlations, is critical to this point, as knowledge of the 'genetic structure' among traits concerned is essential to understanding both the potential and constraints for phenotypic evolution in a particular environment (Loeschcke, 1987). In addition, the existence of negative genetic correlations, referred to as genetic 'trade-offs' between flight capacity and lifehistory traits, especially those fitness-related traits, may be important in the maintenance of genetic variation (Rose, 1983, 1985).

Although genetic trade-offs between flight capacity and various life-history traits are apparent from both the laboratory investigations and field observations (Danthanarayana, 1976a, b) in E. postvittana, the relative advantages associated with the ability to fly in this species are obvious in consideration of its natural habitats. Long-flying ability facilitates escape from deteriorating patches of host plants and the colonization of more nutritious stands that occur elsewhere. The offspring of long-flying individuals, by developing on more nutritious plants, survive better, mature earlier and produce larger adults with a higher fecundity, than they would have if confined to less nutritious plants (Danthanarayana, 1975, 1983; Geier \& Briese, 1981). Under extremely harsh conditions, e.g. dry and hot seasons, such as the 1973 summer in Australia (Danthanarayara, 1983), long-flying forms may well have contributed to survival of this species by preventing the extinction of local populations. The interaction between the flight response to impact of food (water deficit) and climate (temperature) and genetic variability in flight behaviour causes some individuals to be more flight-worthy (Danthanarayana, 1976a, b; H. Gu \& W. Danthanarayana, in preparation). In the context, such interaction would be of adaptive significance to $E$. postvittana. Furthermore, in uncertainly variable environments, high mobility provides an element of behavioural flexibility that allows long-flying forms to compensate partially for their developmental reproductive delay and reduced fecundity, and the genotype with smaller growth rate can achieve high fitness by smaller probability of extinction (Tuljipurkar \& Orzack, 1980).

\section{Acknowledgements}

Thanks are due to Professor J. S. F. Barker for advice on the design and analysis of the experiments and critical reading of the manuscript. This work was supported by grants from the Australian Research Council and the University of New England to W. Danthanara- yana and the research scholarship of the University of New England awared to H. Gu.

\section{References}

BECKER, W. A. 1984. Manual of Quantitative Genetics, 4th edn, Academic Enterprises, Pullman, WA.

BIRCH, L. C. 1948. The intrinsic rate of natural increase of an insect population. J. Anim. Ecol., 17, 15-26.

DANTHANARAYANA, w. 1975 . The bionomics, distribution and host range of the light brown apple moth, Epiphyas postvittana (Walk.) (Tortricidae). Aust. J. Zool. 23, 419-437.

DANTHANARAYANA, w. 1976a. Flight thresholds and seasonal variations in flight activity of the light brown apple moth, Epiphyas postvittana (Walk.) (Tortricidae). Oecologia, 23, 171-182.

DANTHANARAYANA, w. 1976b. Environmentally cued size variation in the light brown apple moth, Epiphyas postvittana (Walk.) (Tortricidae), and its adaptive value in dispersal. Oecologia, 26, 121-132.

Danthanarayana, w. 1983. Population ecology of the light brown apple moth, Epiphyas postvittana (Lepidoptera: Tortricidae). J. Anim. Ecol., 52, 1-33.

DENNO, R. F. OLMSTEAD, K. L. AND McCLOUD, E. S. 1989. Reproductive cost of flight capability: a comparison of life history traits in wing dimorphic planthoppers. Ecol. Entomol., 14, 31-44.

DINGLE, H. 1986. Evolution and genetics of insect migration. In: Danthanarayana, W. (ed.) Insect Flight: Dispersal and Migration, Springer-Verlag, Berlin.

DINGLE, H. LESLIE, J. F. AND PALMER, J. O. 1986. Behavior genetics of flexible life histories in milkweed bugs (Oncopeltus fasciatus). In: Huettel, M. (ed.) Evolutionary Genetics of Invertebrate Behavior. Plenum, New York.

FALCONER, D. S. 1981. Introduction to Quantitative Genetics, 2nd edn, Longman, London.

GEIER, P. W. AND BRIESE, D. T. 1981. The light brown apple moth, Epiphyas postvittana (Walker): a native leafroller fostered by European settlement. In: Kitching, R. L. and Jones, R. E. (eds) The Ecology of Pests: Some Australian Case Histories. CSIRO Australia, Melbourne.

GU, H. AND DANTHANARAYANA, w. 1991. Quantitative genetic analysis of dispersal in Epiphyas postvittana. I. Genetic variation of flight capacity. Heredity, 68, 53-60.

GUREVITCH, J. AND CHESTER, S. T. 1986. Analysis of repeated measures experiments. Ecology, 67, 251-255.

HARVEY, W. R. 1970. Estimation of variance and covariance components in the mixed model. Biometrics, 26, 485-504.

HARVEY, W. R. 1988. Users guide for LSMLMW mixed model least-squares and maximum likelihood computer program Ohio State University, Colonbus, $\mathrm{OH}$.

HEGMANN, J. P. AND DINGLE, H. 1982. Phenotypic and genetic covariance structure in milkweed bug life history taits. In: Dingle, H. and Hegmann, J. P. (eds) Evolution and Genetics of Life Histories. Springer-Verlag, Berlin.

LANDE, R. 1979. Quantitative genetic analysis of multivariate evolution, applied to brain: body size allometry. Evolution, 33, 402-416. 
LAVIE, B. AND RITTE, U. 1978. The relation between dispersal behaviour and reproductive fitness in the flour beetle Tribolium castaneum. Can. J. Genet. Cytol., 20, 589-595.

LOESCHCKE, v. 1987. Genetic Constraints on Adaptive Evolution. Springer-Verlag, Berlin.

PALMER, J. o. 1985. Ecological genetics of wing length, flight propensity, and early fecundity in a migratory insect. In: Rankin, M. A. (ed.) Migration: Mechanisms and Adaptive Significance. Contributions in Marine Science Supplement, 27, 663-673.

PARSONS, M. A. 1983. The Evolution Biology of Colonizing Species. Cambridge University Press, Cambridge.

RITTE, U. AND LAVIE, B. 1977. The genetic basis of dispersal behavior in the flour beetle Tribolium castaneum. Can. J. Genet. Cytol., 19, 717-722.

ROFF, D. A. 1984. The cost of being able to fly: a study of wing polymorphism in two species of crickets. Oecologia, 63, 30-37.

ROFF, D. A. 1990. Antagonistic pleiotropy and the evolution of wing dimorphism in the sand cricket, Gryllus firmus. Heredity, 65, 169-177.

ROSE, M. R. 1982. Antagonistic pleiotropy, dominance and genetic variation. Heredity, 48, 63-78.

RoSe, M. R. 1983. Theories of life-history evolution. Am. Zool., 23, 15-23.

ROSE, M. R. 1985. Life history evolution with antagonistic pleiotropy and overlapping generations. Theor. Pop. Biol., 28, 342-358.

SAFRIEL, U. N. AND RITTE, U. 1980. Criteria for the identification of potential colonizers. Biol. J. Linn. Soc., 13, 287-297.

SERVICE, P. M. AND ROSE, M. R. 1985. Genetic covariation among life-history components: the effect of novel environments. Evolution, 39, 943-945.

SHOREY, H. H. AND HALE, R. L. 1965. Mass-rearing of the larvae of nine noctuid species on a simple artificial medium. $J$. Econ. Entomol., 58, 522-524.

Sibly, R. M. AND CALOW, P. 1986. Physiological Ecology of Animals: An Evolutionary Approach. Blackwell Scientific Publications Ltd, Oxford.

SOKAL, R. R. AND ROHLF, F. J. 1981. Biometry, 2nd edn, W. H. Freeman \& Co., San Francisco.

TAUBER, M. J., TAUBER, C. A. AND MASAKI, S. 1986. Seasonal Adaptation of Insects. Oxford University Press, Oxford.

TUlJAPURKAR, S. D. AND ORZACK, S. H. 1980. Population dynamics in variable environments: I. Long-run growth rates and extinction. Theor. Pop. Biol., 18, 314-342.

ZAR, J. H. 1974. Biostatistical Analysis. Prentice Hall, Inc.

ZIRKLE, D. F., DAWSON, P. S. AND LAVIE, B. 1988. An experimental analysis of the genetic relationships among life-history traits and emigration behavior in Tribolium castaneum. Oikos, 53 391-397. 